\title{
MRI Evaluation of Painful Hip Joint
}

\author{
Sahil Chhabra ${ }^{\oplus 1}$, Navkiran Kaur ${ }^{\circledR 2}$, Simmi Bhatnagar ${ }^{\oplus 3}$, Prerna Chhabra ${ }^{\oplus 4}$, Shivani Puri ${ }^{\circ 5}$ \\ ${ }^{1}$ PG resident, Department of Radio-diagnosis, Government Medical College, Patiala, Punjab, India, ${ }^{2}$ Professor and Head, Department of Radio-diagnosis, Government \\ Medical College, Patiala, Punjab, India, ${ }^{3}$ Associate Professor, Department of Radio-diagnosis, Government Medical College, Patiala, Punjab, India, ${ }^{4}$ Department of \\ Pathology, Guru Gobind Singh Medical College, Faridkot, Punjab, India, ${ }^{5}$ Department of Pathology, Christian Medical College, Ludhiana, Punjab, India.
}

\section{Abstract}

Background: The hip is a stable, major weight-bearing joint with significant mobility. It can be involved by numerous pathological conditions like congenital and developmental, infective, arthritic, and neoplastic. Hence, early diagnosis and characterization of pathology play a vital role for the clinicians in proper management and follow-up of the disease. This study aimed to evaluate the role of MRI in the diagnosis of painful hip pathology. Subjects and Methods: This study was a prospective study; total 50 patients were included in this study. This study was conducted at the Department of Radio-Diagnosis, Rajindra Hospital, Patiala. MR Imaging was done with a 1.5 Tesla superconductive scanner (Siemens 1.5 T Magnetom AERA MRI Machine). Results: 26 out of 69 total hip joints affected (including bilateral) were diagnosed as avascular necrosis, 14 hips as osteoarthritis, and 10 hips as septic arthritis. Inflammatory arthritis was diagnosed in 7 hips, femoroacetabular impingement and an acetabular labral tear in 2 hips each. 2 cases were reported as normal hip joint and 1 case each was reported as a primary and metastatic tumor. Conclusion: MRI is the method of choice in characterizing the various disorders of the hip joint, and it can point out specific features leading to an accurate diagnosis of the painful hip joint.

Keywords: MRI, Hip Joint, Avascular Necrosis, Painful Hip.

Corresponding Author: Navkiran Kaur, Professor and Head, Department of Radio-diagnosis, Government Medical College, Patiala, Punjab, India.

E-mail: sahil.doc.online@gmail.com

Received: 26 March 2020

Revised: 01 May 2020

Accepted: 22 May 2020

Published: 05 July 2020

\section{Introduction}

The hip is a stable, major weight-bearing joint with significant mobility. Since this joint is a complex articulation and can be involved by numerous pathological conditions like congenital and developmental, infective, arthritic, and neoplastic, hence early diagnosis and characterization of pathology plays a vital role for the clinicians in proper management and follow up of the disease. ${ }^{[1]}$ Differential diagnosis of hip pain is exhaustive and includes causes as: ${ }^{[2]}$ Osteonecrosis (Avascular necrosis of femoral head), osteoarthritis, septic arthritis, tubercular arthritis, femoral-acetabular impingement, transient osteoporosis of the hip, occult or stress fracture, transient synovitis, sacroiliitis, malignancy, etc.

Imaging plays a pivotal role in the evaluation of hip pain. Although radiographs provide critical information about the osseous architecture and remain the first line of investigation, they are limited in their capacity to provide a detailed analysis of other key anatomical components and in early detection of pathologies. $^{[3]}$
CT scan can demonstrate bony pathology well, but not as early as MRI. CT scan also has the disadvantage of radiation; however, it can demonstrate bony overgrowth or calcified lesions very well. Radionuclide imaging of painful hip, although sensitive, is not specific for increased uptake of the isotope, and hence the exact nature and extent of the pathology cannot be determined. MRI is often the problem-solving technique by passing bone scintigraphy and CT scanning. ${ }^{[1]}$

Many pathological conditions of the hip are detected early by MRI due to its high soft-tissue resolution and sensitivity. ${ }^{[4]}$

\section{Subjects and Methods}

\section{Source and Method of collection of data}

The main source of the study was patients from the Rajindra Hospital Patiala. All patients referred to the department of Radiodiagnosis, Rajindra Hospital, Patiala from the Department of Orthopaedics, Rajindra Hospital with a clinical history of hip pain were subjected to the study. 
A minimum of 50 cases was intended to be taken up for the study to derive a significant result and statistical analysis.

\section{Inclusion criteria}

The study included patients presenting with acute or chronic hip pain.

\section{Exclusion criteria}

The study excluded

- Patients with a history of acute trauma to hip.

- Patients with a previous history of hip surgery.

- The patient having a history of claustrophobia.

- Patient has a history of ferromagnetic implants, cardiac pacemakers, cochlear implants, and metallic foreign body in situ.

\section{Technique:}

MR Imaging was done with a 1.5 Tesla superconductive scanner (Siemens 1.5 T Magnetom AERA MRI Machine).

For MR imaging, the following sequences were selected as required:

- PD Transverse spin-echo (TR/TE - 3000/34, Slice thickness $-3 \mathrm{~mm}$

- T2 weighted Transverse spin-echo (TR/TE - 9220/96, Slice thickness $-3 \mathrm{~mm}$

- T1 weighted Coronal spin-echo (TR/TE - 800/12, Slice thickness $-3 \mathrm{~mm}$

- T1 weighted Coronal FSE (TR/TE - 710/7 10, Slice thickness $-3 \mathrm{~mm}$

- T2 weighted Coronal 3D (TR/TE - 17 9/6 6, Slice thickness $-08 \mathrm{~mm}$

- T1 weighted Coronal STIR (TR/TE - 3500/31, Slice thickness $-3 \mathrm{~mm}$

The intravenous contrast (Gadolinium in a dosage of 0.1 $\mathrm{mmol} / \mathrm{kg}$ ) was administered intravenously as and when necessary based on the MRI findings and contrast-enhanced MRI was performed on T1 weighted Coronal FSE sequence.

\section{Results}

The present study was conducted in the Department of Radiodiagnosis, Government Medical College and Rajindra Hospital, Patiala to study MRI evaluation of painful hip joint in 50 patients.

The age of the patients presenting with painful hip joints ranged from 10 to 80 years, with a mean age of 40.84 years. Maximum patients were in the age group 30-39 years (30\%) followed by the age group of $40-49$ years $(20 \%)$. There was male predominance with males accounting for $29 / 50$ cases

\begin{tabular}{|lll|}
\hline \multicolumn{3}{|c|}{ Table 1: Age Distribution of Patients with Painful Hip Joints } \\
\hline $\begin{array}{l}\text { Age distribu- } \\
\text { tion in years }\end{array}$ & Frequency & Percentage (\%) \\
\hline $10-19$ & 4 & $8 \%$ \\
$20-29$ & 7 & $14 \%$ \\
\hline $30-39$ & 15 & $30 \%$ \\
\hline $40-49$ & 10 & $20 \%$ \\
\hline $50-59$ & 7 & $14 \%$ \\
$60-69$ & 5 & $10 \%$ \\
\hline $70-80$ & 2 & $4 \%$ \\
\hline TOTAL & 50 & $100 \%$ \\
\hline
\end{tabular}

(58\%) and females accounting for $21 / 50$ cases (42\%), with male to female ratio of 1.4:1. [Table 1]

Out of 50 patients, 19 patients (38\%) presented with bilateral painful hip joints. Whereas, $34 \%$ of patients presented with right-sided and $28 \%$ of patients presented with left-sided painful hip joints. The commonest chief complaint, other than the pain of the involved hip joint, was found to be restricted movement (27 hip joints). Pain radiating to the ipsilateral knee was present 13 hip joints. 11 patients presented with fever and weight loss was present in 3 cases.

The most common MRI finding among 69 painful hip joints (including the bilateral cases) was articular cartilage thinning, present in $38(55 \%)$ hip joints. The next common MRI features were sclerosis, bone marrow edema present in $34(49.3 \%)$, and 33 (47.9\%) painful hip joints, respectively. Subchondral cysts and osteophytes were also commonly seen on MRI in 31 (45\%) and $30(43.5 \%)$ hip joints. The femoral head deformity was present in 28 hip joints $(40.6 \%)$, and features of joint effusion were seen in 22 hip joints (31.9\%).

Synovial enhancement on post-contrast and synovial thickening were seen on MRI in 20 (29\%), and 18 (26\%) affected hip joints. $17(24.6 \%)$ hip joints showed double line sign on MRI, and 13 (18.8\%) hip joints showed subchondral erosions. Features like soft tissue swelling/edema and acetabular protrusion were present in $8(11.6 \%)$ and $3(4.3 \%)$ painful hip joints. [Table 2]

The most common diagnosis of the painful hip joint was avascular necrosis, reported in 26 out of 69 cases (37.68\%) of total hips affected. The next common were osteoarthritis, diagnosed in 14/69 (20.29\%) hip joints and septic arthritis, diagnosed in 10/69 (14.50\%) hip joints. Inflammatory arthritis accounted for 7 out of 69 total hip joints (10.15\%). 2 hip joints were reported as femoral-acetabular impingement and acetabular labral tear each where 2 cases were reported as normal hip joints without any pathology. 1 case each of primary bone tumor and metastatic tumor deposits were also reported. [Table 3] 
Table 2: Distribution of patients according to MRI findings in total painful hip joints.

\begin{tabular}{|c|c|c|}
\hline $\begin{array}{l}\text { MRI FINDINGS in } \\
\text { total painful hip joints } \\
(\mathrm{n}=69)\end{array}$ & $\begin{array}{l}\text { Number of } \\
\text { hip joints }\end{array}$ & Percentage \\
\hline \multicolumn{3}{|l|}{ Bone Marrow Edema } \\
\hline Present & 33 & $47.9 \%$ \\
\hline Absent & 36 & $52.1 \%$ \\
\hline \multicolumn{3}{|l|}{ Sclerosis } \\
\hline Present & 34 & $49.3 \%$ \\
\hline Absent & 35 & $50.7 \%$ \\
\hline \multicolumn{3}{|l|}{ Osteophytes } \\
\hline Present & 30 & $43.5 \%$ \\
\hline Absent & 39 & $56.5 \%$ \\
\hline \multicolumn{3}{|l|}{ Double Line Sign } \\
\hline Present & 17 & $24.6 \%$ \\
\hline Absent & 52 & $75.4 \%$ \\
\hline \multicolumn{3}{|c|}{ Articular Cartilage Thinning } \\
\hline Present & 38 & $55.0 \%$ \\
\hline Absent & 31 & $45.0 \%$ \\
\hline \multicolumn{3}{|l|}{ Joint effusion } \\
\hline Present & 22 & $31.9 \%$ \\
\hline Absent & 47 & $68.1 \%$ \\
\hline \multicolumn{3}{|c|}{ Femoral head deformity/collapse } \\
\hline Present & 28 & $40.6 \%$ \\
\hline Absent & 41 & $59.4 \%$ \\
\hline \multicolumn{3}{|l|}{ Subchondral cysts } \\
\hline Present & 31 & $45.0 \%$ \\
\hline Absent & 38 & $55.0 \%$ \\
\hline \multicolumn{3}{|l|}{ Subchondral erosions } \\
\hline Present & 13 & $18.8 \%$ \\
\hline Absent & 56 & $81.2 \%$ \\
\hline \multicolumn{3}{|l|}{ Acetabular protrusion } \\
\hline Present & 3 & $4.3 \%$ \\
\hline Absent & 66 & $95.7 \%$ \\
\hline \multicolumn{3}{|c|}{ Soft tissue swelling/ edema } \\
\hline Present & 8 & $11.6 \%$ \\
\hline Absent & 61 & $88.4 \%$ \\
\hline \multicolumn{3}{|l|}{ Synovial thickening } \\
\hline Present & 18 & $26.0 \%$ \\
\hline Absent & 51 & $74.0 \%$ \\
\hline \multicolumn{3}{|c|}{ Synovial enhancement on post-contrast } \\
\hline Present & 20 & $29.0 \%$ \\
\hline Absent & 49 & $71.0 \%$ \\
\hline
\end{tabular}

Table 3: Distribution of a total number of hip joints (including bilateral cases) affected according to diagnosis on MRI.

\begin{tabular}{|c|c|c|c|}
\hline \multicolumn{4}{|c|}{ Diagnosis of MRI $(n=69)$} \\
\hline Diagnosis & & $\begin{array}{l}\text { No. Of } \\
\text { Hips } \\
\text { affected }\end{array}$ & Percentage \\
\hline \multicolumn{2}{|c|}{ Avascular necrosis } & 26 & $37.68 \%$ \\
\hline \multicolumn{2}{|c|}{ Osteoarthritis } & 14 & $20.29 \%$ \\
\hline \multirow[t]{2}{*}{ Infective } & $\begin{array}{l}\text { Septic } \\
\text { arthritis }\end{array}$ & 10 & $14.50 \%$ \\
\hline & $\begin{array}{l}\text { Tubercular } \\
\text { arthritis }\end{array}$ & 4 & $5.80 \%$ \\
\hline \multicolumn{2}{|c|}{ Inflammatory arthritis } & 7 & $10.15 \%$ \\
\hline \multirow[t]{2}{*}{ Tumor } & Primary & 1 & $1.44 \%$ \\
\hline & Metastasis & 1 & $1.44 \%$ \\
\hline \multicolumn{2}{|c|}{$\begin{array}{l}\text { Femoro-acetabular } \\
\text { impingement }\end{array}$} & 2 & $2.90 \%$ \\
\hline \multicolumn{2}{|c|}{$\begin{array}{l}\text { Acetabular labral tear with } \\
\text { effusion }\end{array}$} & 2 & $2.90 \%$ \\
\hline \multicolumn{2}{|l|}{ Normal } & 2 & $2.90 \%$ \\
\hline \multicolumn{2}{|l|}{ Total } & 69 & $100.00 \%$ \\
\hline
\end{tabular}

Most common MRI findings in a different diagnosis

Table 4: Distribution of patients diagnosed as Avascular necrosis (most common diagnosis) according to MRI findings ( $n=26)$

\begin{tabular}{lll}
\hline Mri findings & $\begin{array}{l}\text { Number } \\
\text { hip joints }\end{array}$ & Percentage \\
\hline Bone marrow edema & 12 & $46.2 \%$ \\
\hline $\begin{array}{l}\text { Sclerosis } \\
\text { Osteophytes }\end{array}$ & 13 & $50.0 \%$ \\
\hline $\begin{array}{l}\text { Double line sign } \\
\text { Articular cartilage thin- } \\
\text { ning }\end{array}$ & 11 & $38.5 \%$ \\
\hline $\begin{array}{l}\text { Joint effusion } \\
\text { Femoral head defor- } \\
\text { mity/collapse }\end{array}$ & 15 & $65.4 \%$ \\
\hline $\begin{array}{l}\text { Subchondral cysts } \\
\text { Subchondral erosions }\end{array}$ & 7 & $42.3 \%$ \\
Acetabular protrusio & 0 & $15.4 \%$ \\
\hline $\begin{array}{l}\text { Soft tissue swelling/ } \\
\text { edema }\end{array}$ & 0 & $57.7 \%$ \\
\hline $\begin{array}{l}\text { Synovial thickening } \\
\text { Synovial enhancement } \\
\text { (on post contrast) }\end{array}$ & 0 & $00.0 \%$ \\
\hline
\end{tabular}




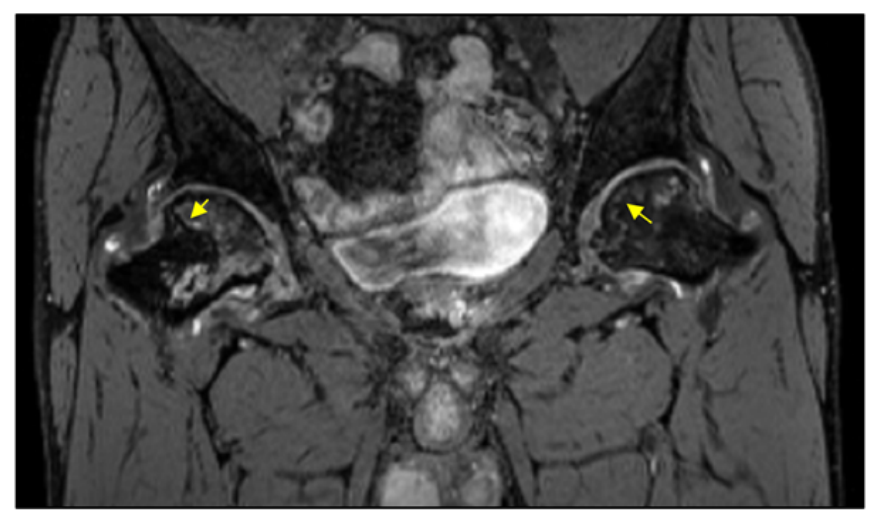

Figure 1: Coronal T2WI of a $50 \mathrm{Y}$ male withBilateral Hip Avascular Necrosis show double line sign of AVN bilaterally (yellow arrows) and irregular contour of both femoral heads.

The most common MRI finding was a double line sign seen in 17 out of 26 hip joints diagnosed as avascular necrosis. The next common findings were femoral head deformity/collapse and sclerosis seen in 15 hips (57.7\%) and 13 hips (50\%), respectively. The most common MRI finding for the diagnosis of osteoarthritis was articular cartilage thinning, which was present in all the 14 hip joints followed by the presence of osteophytes and subchondral cysts in 13 hip joints each. [Table $4]$.

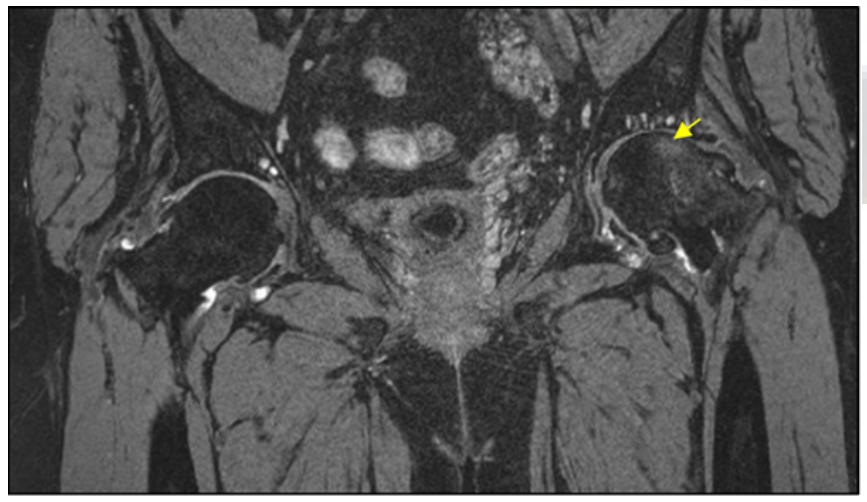

Figure 2: Coronal T2WI of a $50 \mathrm{Y}$ female withBilateral Hip Osteoarthritis showing osteophytes, subchondral cysts along acetabular surfaces bilaterally. Also seen is bone marrow edema (yellow arrow) in the left femoral head and neck.

Out of 10 hip joints diagnosed as septic arthritis, the most common MRI findings were synovial enhancement on postcontrast, joint effusion, and bone marrow edema, which were present in 9 hip joints (90\%). Also commonly seen on MRI in

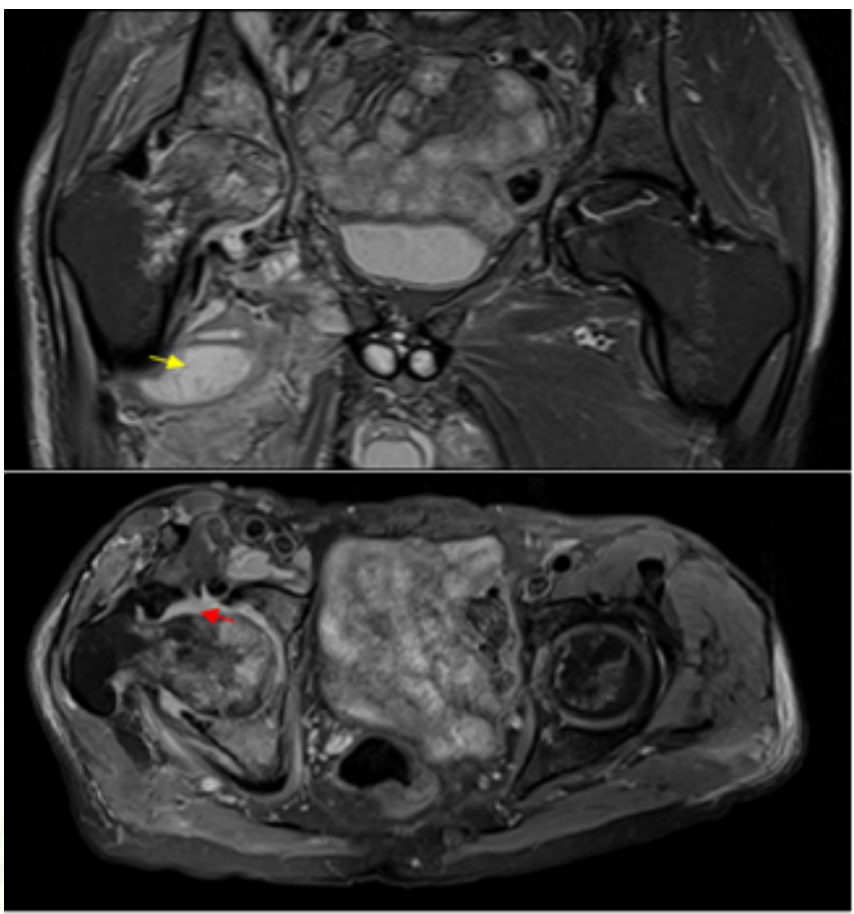

Figure 3: (a\& b) 75 Y old male with Right Side Tubercular ArthritisWith Left Sided Avascular Necrosis Of Hip (a.) Coronal T1 STIR images and (b.) Axial PDFS images show the altered contour of the right femoral head with articular cartilage thinning. Bone marrow edema is seen in the right femoral head, neck and right acetabulum. Right-sided synovial thickening (red arrow) is seen along with soft tissue edema/collection (yellow arrow). The left side hip shows a double line sign of avascular necrosis.

cases of septic arthritis was synovial thickening, present in 8 hip joints (80\%).

The most common MRI finding, present in all the 7 hip joints $(100 \%)$ diagnosed as inflammatory arthritis, was a synovial enhancement on post-contrast. The next common MRI findings were synovial thickening, articular cartilage thinning, subchondral cysts, subchondral erosions and sclerosis, which were present in 6 hip joints (85.7\%) each.

Out of 4 hip joints diagnosed as tubercular arthritis, the most common MRI findings were synovial enhancement on post-contrast, synovial thickening and bone marrow edema, which were present in all the hip joints (100\%). The most common MRI findings, present in both of the hip joints (100\%) diagnosed as femoral-acetabular impingement, were femoral head deformity/collapse, subchondral cysts, and articular cartilage thinning. 
Both the hip joints (100\%) diagnosed with tumor/ mitotic pathology showed synovial enhancement on post-contrast on MRI. Both of the hip joints diagnosed as acetabular labral tear showed joint effusion each (100\%) on MRI.

\section{Discussion}

Our study showed the maximum no. of patients with painful hip joint falling in the age group of 31-40 years with a mean age of 40.84 years and male predominance with male to the female sex ratio of 1.4:1. Similarly, Kondeti et al, ${ }^{[5]}$ observed the maximum no. of patients with nontraumatic hip joint pain falling in the age group of 31-40 years with a male to female ratio of 2.8:1.

Reddy et al, ${ }^{[6]}$ showed the mean age of patients with nontraumatic hip pain to be 44 years and a male to female ratio of 3:1. RamBhamu et al, ${ }^{[7]}$ in their study on MRI of the painful hip joint, found the male to female ratio of 2.3:1.

In our study, 31 patients had unilateral 'hip pain', which amounts to $62 \%$ of total patients while 19 patients had bilateral 'hip pain', i.e. $38 \%$ of cases $(n=50)$. This data is following the data showed by Dutta et al, ${ }^{[1]}$ in their study on imaging of hip pathologies where the $66.6 \%$ pathologies detected were unilateral while $33.3 \%$ were bilateral.

Our study observed that the most common underlying pathology of the painful hip joint was avascular necrosis in $37.68 \%$ of cases. The next common was osteoarthritis diagnosed in $20.29 \%$ of cases followed by septic arthritis in $14.5 \%$ of cases and inflammatory arthritis accounting for $10.15 \%$ of cases. Drar et al, ${ }^{[8]}$ Kalekar et al, ${ }^{[9]}$ and Reddy et al, ${ }^{[6]}$ also showed avascular necrosis as the most common diagnosis in non-traumatic hip pain followed by osteoarthritis.

\section{$\underline{\text { Avascular necrosis }}$}

Among the MRI findings, most common were double line sign (65.4\%) and femoral head deformity/collapse (57.7\%) followed by sclerosis, bone marrow edema, and Articular cartilage thinning. MRI findings in a study done by Rekha et al, ${ }^{[10]}$ were bone marrow edema $(69.3 \%)$, sclerosis $(50.8 \%)$, subchondral cysts $(49.2 \%)$, double line sign (43.1\%). Vaghamashi et al, ${ }^{[11]}$ observed that the most common findings on MRI in patients with avascular necrosis of femoral head were focal subchondral signal abnormality (100\%) and hip joint effusion $(65.2 \%)$.

\section{$\underline{\text { Osteoarthritis }}$}

The most common MRI findings in the patients with hip osteoarthritis as articular cartilage thinning (100\%), subchondral cysts $(92.8 \%)$ and osteophytes $(92.8 \%)$ followed by sclerosis $(64.2 \%)$, and bone marrow edema $(42.8 \%)$. Vaghamashi et al, ${ }^{[11]}$ in their study showed the common MRI findings of hip osteoarthritis were osteophytes (100\%), loss of articular cartilage $(66.6 \%)$ similar to our study and followed by joint effusion, subchondral cysts, and bone marrow edema.

\section{Septic arthritis}

The most common MRI findings in our study were bone marrow edema (90\%), joint effusion (90\%), synovial thickening $(80 \%)$ and enhancement (90\%), and soft tissue edema (40\%). Luhmann et al, ${ }^{[12]}$ found synovial enhancement and perisynovial edema as the most common MRI finding in septic arthritis. The study done by El-Zawawi et al, ${ }^{[13]}$ revealed the MRI findings in septic arthritis of hip were synovial thickening, joint effusion, soft-tissue edema, and bone marrow edema. Narra et al, ${ }^{[14]}$ found the common MRI findings in patients with septic arthritis of hip as joint space narrowing, joint effusion, and periarticular soft-tissue edema.

\section{Tubercular arthritis}

The most common MRI findings were: bone marrow edema, synovial thickening, and enhancement. Prakash et al, ${ }^{[15]}$ and Kalekar et al, ${ }^{[9]}$ also found bone marrow edema along with joint effusion and soft tissue lesions as the most common findings in tubercular arthritis.

\section{Inflammatory arthritis}

The majority of the findings on MRI were synovial thickening and enhancement followed by subchondral cysts and erosions. Dutta et al, ${ }^{[1]}$ showed joint space reduction and marginal erosions as the most common MRI findings, whereas Kondeti et al, ${ }^{[5]}$ found joint effusion, bone marrow edema, and erosions most commonly in inflammatory arthritis.

\section{$\underline{\text { Neoplastic (tumor/metastasis) }}$}

Our study had 2 cases out of 50 (4\%) with neoplasia as a diagnosis, and both of them were unilateral. Hence, 2 out of 69 hips $(2.88 \%)$ were affected. One of them was a case of the primary tumor and the other was metastatic, leading to $1.4 \%$ of total hips affected with each. This is in concordance with the study conducted by Vaghamashi et al, ${ }^{[11]}$ where neoplastic etiology was a cause of hip pain in $3.84 \%$ of the cases.

\section{Femoroacetabular impingement}

Out of 69 hips $(2.9 \%)$ were affected with FAI. Both of them had CAM type FAI in the neck of the femur. Vaghamashi et al, ${ }^{[11]}$ similarly showed the percentage of cases with a femoroacetabular impingement in their study as $1.92 \%$. 


\section{Acetabular labral tear}

One patient $(2 \%, \mathrm{n}=50)$ was found to have an acetabular labral tear in both of the hip joints along with bilateral joint effusion hence showing 2 hips (5.88\%) involved with this diagnosis out of a total 69 hips.

\section{Conclusion}

In this study, we reached that MRI is the method of choice in characterizing the various disorders of the hip joint and it can point out specific features leading to accurate diagnosis of the painful hip joint. It is an accurate imaging modality for assessing the full extent of osseous, chondral, and soft tissue abnormality of the hip joint. MR imaging can also accurately demonstrate joint effusions, synovial proliferation, articular cartilage abnormalities, subchondral bone, ligaments, muscles, and juxta-articular soft tissues. Due to good resolution, improved differentiation of tissue contrast, and capacity for multiplanar imaging, MRI is the diagnostic modality of choice for assessment of hip disorders.

\section{References}

1. Dutta P, Sonowal TN, Shahare SL, Asthana K. Imaging of Hip Joint Pathologies. J Evol Med Dent Sci. 2016;5(63):44304436. Available from: https://dx.doi.org/10.14260/jemds/2016/ 1012.

2. Wilson JJ, Furukawa M. Evaluation of the patient with hip pain. Am Fam Physician. 2014;89(1):27-34.

3. Mitchell DG, Rao VM, Dalinka M, Spritzer CE, Axel L, Gefter $\mathrm{W}$, et al. Hematopoietic and fatty bone marrow distribution in the normal and ischemic hip: new observations with 1.5-T MR imaging. Radiology. 1986;161(1):199-202. Available from: https://dx.doi.org/10.1148/radiology.161.1.3763867.

4. Santiago FR, Chinchilla AS, Ansari A, Álvarez LG, del Mar Castellano García M, Martínez AM, et al. Imaging of Hip Pain: From Radiography to Cross-Sectional Imaging Techniques. Radiol Res Pract. 2016;2016:1-15. Available from: https://dx. doi.org/10.1155/2016/6369237.

5. Kondeti D, Gangishetty S. MRI evaluation of nontraumatic hip joint pain. Int J Sci. 2017;6(10):479-481.

6. Reddy KV, Kapoor A. MR Evaluation of Non-Traumatic Hip Pain. JMSCR. 2017;05(03):19090-101.
7. RamBhamu S, Kardam N, Gehlot K, Khan A. The Role Of MRI In The Evaluation Of Painful Hip Joint. IRPMS. 2017;3(2):112.

8. Drar HAEAE. The Role of MRI in the Evaluation of Painful Hip Joint (MRI of Hip Joint). Int J Med Imaging. 2014;2(3):77-82. Available from: https://dx.doi.org/10.11648/j.ijmi.20140203. 16.

9. Kalekar T, Shriramwar P. Role of magnetic resonance imaging findings in the evaluation of painful hip joint. Int $\mathrm{J}$ Med. 2017;3(7):105-111.

10. Rekha KA, Garg Y, Kaur N, Malik P. Role of Plain Radiography and MRI in the Evaluation of Avascular Necrosis of Head of Femur. Int J Sci. 2019;8(11):433-437.

11. Vaghamashi A, Bhatt J, Doshi J, Patel V. MRI in Evaluation of painful Hip Joint. J Appl Dent. 2017;16(5):85-96.

12. Luhmann SJ, Jones A, Schootman M, Gordon JE, Schoenecker PL, Luhmann JD. Differentiation Between Septic Arthritis and Transient Synovitis of the Hip in Children with Clinical Prediction Algorithms. J Bone Joint Surg. 2004;86(5):956962. Available from: https://dx.doi.org/10.2106/00004623200405000-00011.

13. Zawawi MSEDE, Habib RM, Zefzaf DAERE. Role of magnetic resonance imaging in the assessment of chronic hip pain in adults. Menoufia Med J. 2018;31:514-523.

14. Narra RK, Kolipe SP, P BR, Putcha A. Magnetic resonance imaging in the evaluation of painful hip joint. JEBMH. 2018;5(50):3406-3412. Available from: https://dx.doi.org/10. 18410/jebmh/2018/694.

15. Prakash A, Hegde SA, Vedaraju KS, Benegal DS. Evaluation of Hip Disorders Using Magnetic Resonance Imaging. Int J Anat Radiol Surg. 2019;8(3):21-25.

Copyright: (C) the author(s), 2020. It is an open-access article distributed under the terms of the Creative Commons Attribution License (CC BY 4.0), which permits authors to retain ownership of the copyright for their content, and allow anyone to download, reuse, reprint, modify, distribute and/or copy the content as long as the original authors and source are cited.

How to cite this article: Chhabra S, Kaur N, Bhatnagar S, Chhabra P, Puri S. MRI Evaluation of Painful Hip Joint. Asian J. Med. Radiol. Res. 2020;8(1):122-127.

DOI: dx.doi.org/10.47009/ajmrr.2020.8.1.22

Source of Support: Nil, Conflict of Interest: None declared. 